Reprinted with permission from: Weed Science. January 1985. 34(1): 57-61.

Published and copyrighted by: Weed Science Society of America. http://www.wssa.net

\title{
Predicting weed migration from soil and climate maps ${ }^{1}$
}

\author{
TIMOTHY K. CHICOINE, PETER K. FAY, and GERALD A. NIELSEN \\ Res. Asst., Assoc. Prof., and Prof., Plant and Soil Sci. Dep., Montana State Univ., Bozeman, MT 59717, respectively
}

\begin{abstract}
:
Soil characteristics, elevation, annual precipitation, potential evapotranspiration, length of frost-free season, and mean maximum July temperature were estimated for 116 established infestations of spotted knapweed (Centaurea maculosa Lam. \#² CENMA) in Montana using basic land resource maps. Areas potentially vulnerable to invasion by the plant were delineated on the basis of representative edaphic and climatic characteristics. No single environmental variable was an effective predictor of sites vulnerable to invasion by spotted knapweed. Only a combination of variables was effective, indicating that the factors that regulate adaptability of this plant are complex. This technique provides a first approximation map of the regions most similar environmentally to infested sites and, therefore, most vulnerable to further invasion. This weed migration prediction technique shows promise for predicting suitable habitats of other invader species.
\end{abstract}

\section{Additional index words:}

Weed distribution, rangeland, mapping, Centaurea maculosa, CENMA.

\section{Introduction}

Spotted knapweed, leafy spurge (Euphorbia esula L. \# EPHES), and other weeds have spread to infest thousands of hectares of rangeland in Montana in the last 80 years

\footnotetext{
${ }^{1}$ Received for publication on April 16, 1985, and in revised form July 10, 1985. Published with the approval of the Dir., Montana Agric. Exp. Stn., Bozeman, as J. Art. No. J-1653.

${ }^{2}$ letters following this \# symbol are a WSSA-approved computer code from Composite List of Weeds, Weed Sci. 32, Suppl. 2. Available from WSSA, 309 West Clark St., Champaign, IL 61820.
} 
(2). The impact of these infestations on otherwise productive lands has been devastating. Identification of uninfested areas susceptible to invasion by these and other weed species would permit land managers to implement preventive weed control measures such as controlled grazing and spot spraying with herbicides. It is critical to protect vast, extensively managed rangeland from weed invasion since most weed control practices are not economically feasible for large, established infestations on low-value land.

Successful plant establishment is governed by edaphic and climatic characteristics that include soil type, elevation, annual precipitation, potential evapotranspiration, length of frost-free season, and the mean maximum July temperature. These characteristics have been routinely published on land resource maps of individual states. Few attempts have been made to use edaphic or climatic characteristics to predict which weed species will become important in a region.

Reuss and Bachthaler (6) produced a correlation index derived from weed surveys and meteorological factors associated with the presence of various weed species. Conversely, Duke (1) used perennial weeds as indicators of the annual climatic parameters of a given area. Lindsay (5) conducted a frequency survey of weed infestations in Wisconsin and correlated the frequency of occurrence with July evaporation. He concluded that the range of adaptation of a weed species could be deduced from climatic data. Harris and Cranston (3) estimated the area susceptible to invasion by diffuse knapweed (Centaurea diffusa Lam. \# CENDI) and spotted knapweed in Canada by comparing soil types in Canada to soils that support diffuse knapweed at the center of origin of the plant.

Spotted knapweed was first reported in Montana in the mid-1920's, and it now infests almost 800,000 ha in the state. The present areas of infestation are primarily located west of the Continental Divide; however, small infestations exist in eastern Montana and the plant is rapidly spreading to new areas in Montana, Idaho, Washington, Oregon, British Columbia, Alberta, North and South Dakota, and Wyoming.

This study was conducted to determine the areas of Montana that may be threatened by invasion of spotted knapweed.

\section{Materials and methods}

One hundred sixteen infestations of spotted knapweed located in 16 counties were used for this study (Figure 1). The infestations were selected with the help of county weed supervisors who prepared maps showing nearly all of the infested sites in their respective coun-

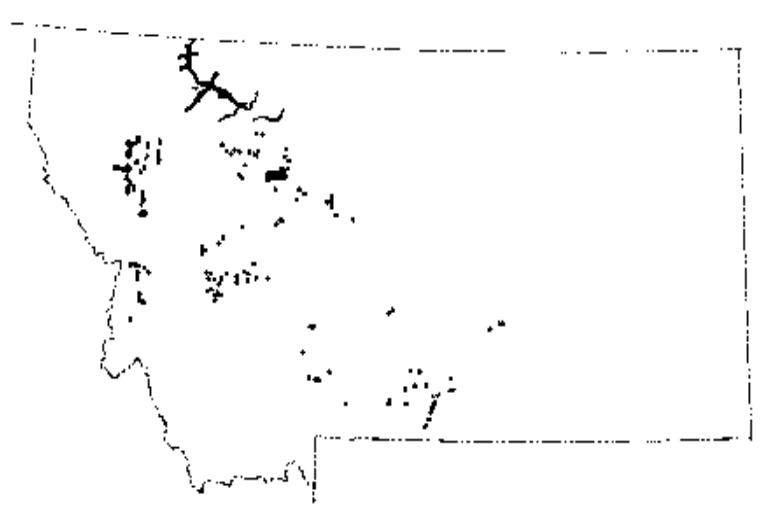

Figure 1. The location of 116 spotted knapweed infestations in Montana. Dots show approximate locations but exaggerate the area infested. The edaphic and climatic characteristics of the infested sites were used to delineate other areas of the state where similar characteristics occur and where spotted knapweed might therefore thrive.

Page 2 of 7 
ties. Sites for the study were selected (after observation) from diverse habitats to avoid sampling bias. Each of the selected infestations covered at least 0.4 ha and was well established on grazing land. Small infestations on disturbed sites such as roadsides and railroad beds were not included.

The infestations were plotted on individual maps for each edaphic and climatic characteristic. The frequency of occurrence of the infestations was calculated in each zone for annual precipitation, elevation, length of frost-free season, potential evaporation, and mean maximum July temperature. If an infestation occurred on the boundary between two zones, that infestation was counted as being in both zones. Thus, the total number of infestations on these maps exceeded 116 in several instances. High-frequency zones for each characteristic, identified from the frequency distributions for each variable, were arbitrarily defined as zones having more than $10 \%$ of the 116 infestations. The individual composite map that contained the high-frequency zones for each individual characteristic contained at least $70 \%$ of the 116 infestations.

Percent frequency and range of occurrence, respectively, for the 116 spotted knapweed infestations were: For annual precipitation, $82 \%$ of the test infestations were found within a range of 31 to $76 \mathrm{~cm}$ of rainfall per year, $90 \%$ of the test infestations were found at elevations ranging from 610 to $1829 \mathrm{~m}, 92 \%$ of the test sites occurred in areas with 50 to 130 frost-free days, the potential evapotranspiration of $72 \%$ of the test sites ranged from 39.7 to $63.5 \mathrm{~cm} /$ year, and the mean maximum July temperature at $72 \%$ of the test sites was 26.6 to $30.0^{\circ} \mathrm{C}$.

Because of the large number of soil mapping units in Montana, it was impossible to construct a frequency distribution for the test infestations. Therefore, if a spotted knapweed infestation occurred on a soil association identified by a given mapping symbol, we assumed that the plant had the ability to occupy soils identified by that same mapping symbol throughout the state.

Individual acetate overlays highlighting the high frequency areas for each climatic and edaphic characteristic were created using acetate blockout film ${ }^{3}$. Individual acetate maps for each characteristic were placed on top of each other to create a composite map with a "shaded window" effect. The potential for an area to support the growth of spotted knapweed was determined by the degree of shading of the composite (the darker the map, the greater the probability of spotted knapweed growth). Regions of the state with the highest probability of invasion were darkest, since all six characteristics indicated these regions have climatic and edaphic characteristics that are similar to the 116 knapweed infestations.

High-probability composite single acetate overlays were constructed that contained regions that have at least four of the six edaphic and climatic characteristics similar to the 116 knapweed infestations in the survey. The high probability composites were then compared to the distribution of the 116 test infestations to check the accuracy of the prediction model. Comparisons were also made against climax vegetation maps (4) to determine whether spotted knapweed poses a threat to distinct climax vegetation zones in the state.

${ }^{3}$ Chart-pak Corp., Cincinnati, OH.

Page 3 of 7 


\section{Results and discussion}

The soil map indicates that most areas in Montana have soils capable of supporting spotted knapweed stands (Figure 2a). Elevation (Figure 2b) also does not restrict spotted knapweed adaptibility since $63 \%$ of the test infestations occurred at elevations ranging from 914 to $1524 \mathrm{~m}$. More than $90 \%$ of the stands occurred at elevations ranging from 610 to $1829 \mathrm{~m}$, but only $14 \%$ of the test infestations occurred at the highest elevations represented (1829 to $2743 \mathrm{~m}$ ) by the test sites.

Slightly less of the state is similar in annual precipitation to the locations of the 116 spotted knapweed infestations (Figure 2c). Nearly $82 \%$ of the test sites occurred where precipitation ranged from 31 to $76 \mathrm{~cm} /$ year. Ten and $23 \%$ of the infestations were found in areas where annual precipitation ranged from less than 25 to $31 \mathrm{~cm}$, and 76 to $203 \mathrm{~cm}$, respectively, indicating that spotted knapweed tolerates a broad range of annual precipitation.
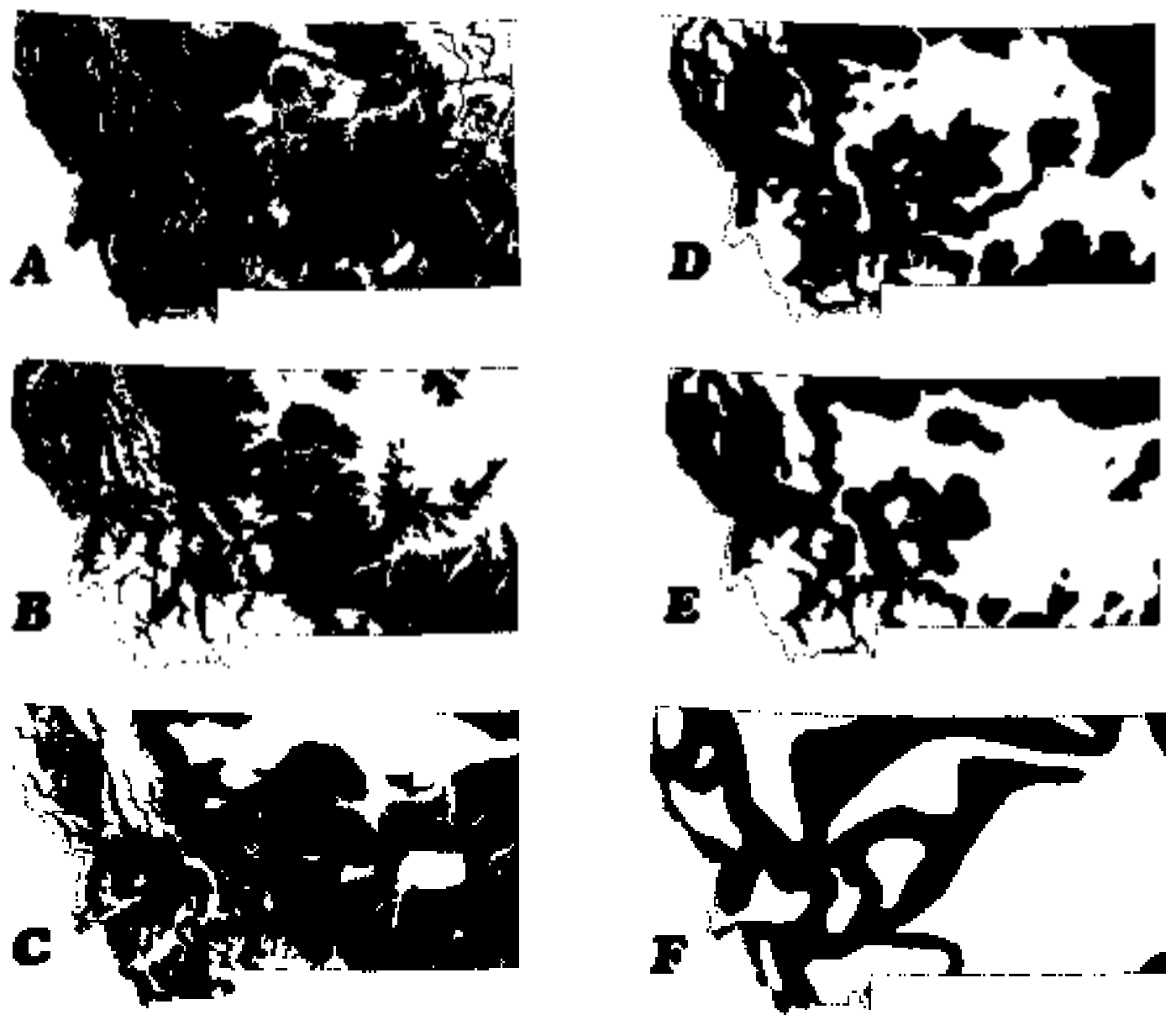

Figure 2. The areas marked in black represent areas which have: a) soils b) elevations c) annual precipitation d) frost-free periods. e) potential evapotranspiration and f) a mean maximum July temperature that support the growth of spotted knapweed. 
Three percent of the spotted knapweed was found in areas with a frost-free season ranging from only 30 to 50 days. The majority (69\%) occurred in areas with 90 to 120 frost-free days (Figure 2d). Approximately $21 \%$ of the test sites occurred in areas with 120 to more than 130 frost-free days. The potential evapotranspiration (PET) map indicates that a smaller portion of the state is similar in this characteristic to infested areas (Figure 2e). Seventy-two percent of the test sites were found in areas where the PET ranged from 39.7 to $63.5 \mathrm{~cm} / \mathrm{yr}$ (Figure 2e). Five percent of the sites occurred in highevaporative regions where the PET ranged from 73.7 to $80 \mathrm{~cm} /$ year.

The variable mean maximum July temperature (Figure $2 \mathrm{f}$ ) may be important for spotted knapweed adaptibility since $72 \%$ of the infestations were found in areas where the range $\left(26.6\right.$ to $\left.30.0^{\circ} \mathrm{C}\right)$ was fairly narrow. Eighteen and $19 \%$ of the remaining infestations were located in areas where the mean maximum July temperature was less than 23.3 to $26.6^{\circ} \mathrm{C}$, and 30 to greater than $32.2^{\circ} \mathrm{C}$, respectively, indicating spotted knapweed will become established in areas with a broad temperature range. The high-frequency zones used for map construction for each characteristic are shown in Table 1.

Table 1. The zones of five climatic and edaphic characteristics that contain the largest percentage of 116 spotted knapweed infestations selected for the study.

\begin{tabular}{lcc}
\hline Characteristics & High-frequency zone & $\begin{array}{c}\text { Infestations within the } \\
\text { high-frequency zone }\end{array}$ \\
\hline & & $(\%)$ \\
Annual precipitation & $30.5-76.2 \mathrm{~cm}$ & 81 \\
Elevation & $1219-1829 \mathrm{~m}$ & 80 \\
Length of frost-free season & $50-120$ days & 81 \\
Potential evapotranspiration & $39.7-63.5 \mathrm{~cm}$ & 72 \\
Mean maximum July temperature & $26.6-30.0^{\circ} \mathrm{C}$ & 72 \\
\hline
\end{tabular}

Since the ability of a plant to grow in a given location is normally governed by more than one factor, composite maps present a clearer view of Montanas vulnerability to invasion by spotted knapweed than do the individual edaphic and climatic characteristic maps. A composite map that includes the high-frequency zones for all six edaphic and climatic characteristics was constructed (Figure 3a). It highlights regions that have environmental characteristics most similar to areas already supporting spotted knapweed growth and suggests areas most vulnerable to further invasion. However, $70 \%$ of the original 116 survey infestations occur outside this shaded area. More than $95 \%$ of the original survey points were included in the shaded zone when it was expanded to represent any region with at least four environmental characteristics similar to the survey infested sites (Figure 3b). Shaded parts of Figure 3b represent areas likely to be more vulnerable to spotted knapweed invasion than other areas of the state but less vulnerable than areas depicted in Figure 3a. Figure $3 \mathrm{~b}$ indicates that nearly $40 \%$ of Montana, or 15 million ha, is threatened by spotted knapweed.

The climax vegetation maps of Kuchler (4) were compared to Figure 3b. There is a similarity between areas delineated in Figure $3 \mathrm{~b}$, and a habitat dominated by ponderosa 
pine (Pinus ponderosa Dougl.), Douglas fir (Pseudotsuga menziesii var. viridis), and the foothills prairie habitat which consists of bluebunch wheatgrass [Agropyron spicatum (Pursh.) Scribn. \& Smith], needleandthread grass (Stipa comata Trin. \& Rupr. \# STDCO), and Idaho fescue (Festuca idahoensis Elmer) in the western and south-central parts of the state (Figure 4). Presently, spotted knapweed is not a problem in the ponderosa pine ecosystems of south-central Montana but is generally a problem in the other habitats. Initiating spotted knapweed awareness programs in areas that appear to have a high potential for supporting infestations may prevent or lessen future problems with this plant. Local weed control personnel can closely monitor specific vegetative communities if a given weed is likely to be adapted to that habitat, and preventive weed control programs could be initiated without delay.

This technique of predicting weed migration has several limitations: a) a reliable, unbiased method of selecting test infestations must be used, and it is critical that the full range of infested sites be selected as test infestations, since omission of certain habitat types will lead to their omission from the regions determined to be threatened; b) there is no statistical analysis built into the model; therefore, the method is descriptive; c) the scale of land resource maps is $1: 1,000,000$; therefore, the technique is limited to identifying threatened regions rather than specific locations; and d) the technique does not consider the role of competition or range condition in limiting plant invasions. Range condition is a critical factor that regulates the rate of establishment of range weeds and tends to vary greatly within a given region in Montana based on the quality of range management implemented.

This technique could be adapted for other troublesome plants of uncultivated land and prove valuable for developing programs to protect vast, extensively managed range and forest resources from weed invasion. It is simple and easy to
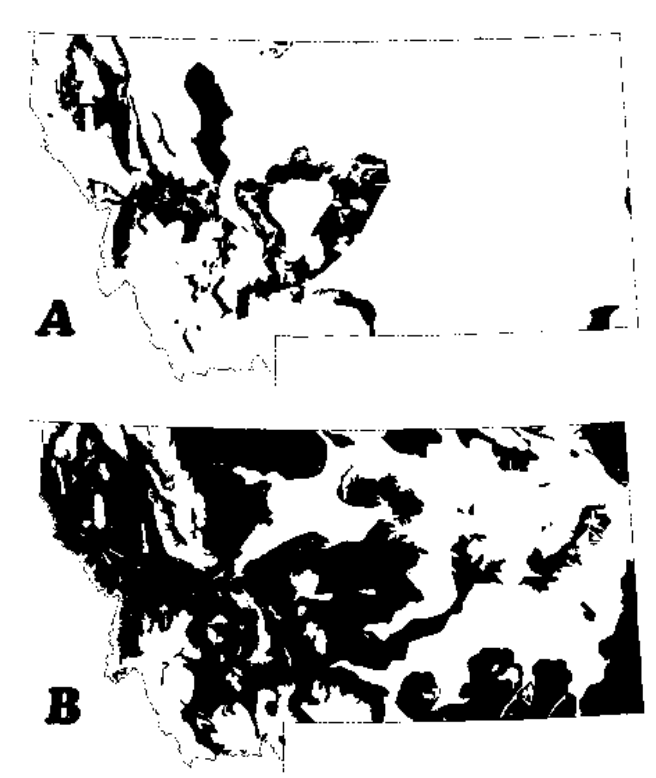

Figure 3. Areas of Montana that contain: a) all six, or b) any four of six representative environmental characteristics that support the growth of spotted knapweed. A representative characteristic was arbitrarily defined as one that represents more than $70 \%$ of the 116 spotted knapweed infestations in this study.

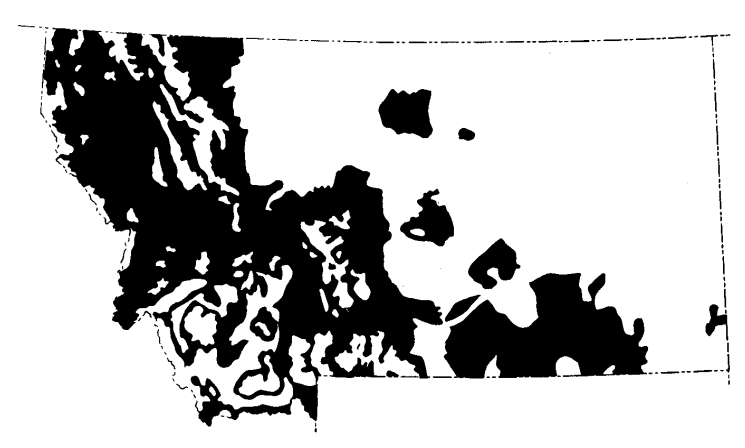

Figure 4. A climax vegetation map adapted from Kuchler (4) where the areas represented in black are dominated by ponderosa pine, Douglas fir, and the foothills prairie habitat. This area is similar to some areas shown to be threatened by spotted knapweed in Figure 3. 
use. It requires no special equipment other than land resource maps, acetate blockout film, and a light table; and no technical knowledge concerning predictive modeling is needed.

\section{Literature cited}

1. Duke, J. A. 1976. Perennial weeds as indicators of annual climatic parameters. Agric. Meteorol. 16:291-294.

2. Forcella, F. and S. J. Harvey. 1981. New and exotic weeds of Montana. II. Migration and distribution of 100 alien weeds in the northwestern U.S.A. 1881-1980. Montana Dep. Agric., Helena, MT. 117 pp.

3. Harris, P. and R. Cranston. 1979. An economic evaluation of control methods for diffuse and spotted knapweed in western Canada. Can. J. Plant Sci. 59:375-382.

4. Kuchler. A. W. 1964. Potential natural vegetation of the conterminous United States. Am. Geographical Soc. Special Publ. No. 36. 116 pp.

5. Lindsay, D. R. 1953. Climate as a factor influencing the mass ranges of weeds. Ecology 34:308-321.

6. Reuss, H. U. and G. Bachthaler. 1979. Review about state and trend of the weed flora on arable land influenced by ecological and anthropogenic factors. IX Int. Congr. of Plant Prot. and 71st M. Am. Phytopath. Soc. No. 99. 